\title{
Dynamics of the pseudolysogenic response in slowly growing cells of Pseudomonas aeruginosa
}

\author{
Steven Ripp† and Robert V. Miller \\ Author for correspondence: Robert V. Miller. Tel: +1 4057447180 . Fax: +14057446790. \\ e-mail: rum67@okway.okstate.edu
}

Department of Microbiology and

Molecular Genetics,

Oklahoma State University,

Stillwater, OK 74078, USA

\begin{abstract}
Pseudolysogeny is an environmental condition in which the starved bacterial cell coexists in an unstable relationship with infecting viral genomes. As nutrients are supplied to the bacterium, the pseudolysogens resolve into either true lysogeny or active production of virions. The direct result of pseudolysogenic relationships is an extension of the effective phage half-lives in natural environments. In this paper a continuous culture model of interactions between bacterial host organisms and bacteriophages leading to pseudolysogeny is presented. The pseudolysogenic state was found to depend on the concentration of nutrients available to the host. As cells became more starved, the frequency of pseudolysogens increased. The dependence on overall nutrient concentration was more dramatic than the variation in the generation time (chemostat turnover time) of the host. Thus, it appears that pseudolysogeny is a legitimate strategy for environmental bacteriophages to adapt to survive periods of starvation of their host organisms. Consideration of pseudolysogeny as a survival strategy is important to the development of any comprehensive model of host-bacteriophage relationships in natural environments.
\end{abstract}

Keywords: pseudolysogeny, Pseudomonas aeruginosa, environmental microbiology, host-bacteriophage interactions

\section{INTRODUCTION}

Our laboratory is constructing a model of hostbacteriophage interactions in natural environments. Previous models have relied on data gathered from experiments in which well-fed cells were analysed under laboratory growth conditions. Our studies, using lownutrient parameters and generation times that are typically encountered in natural ecosystems, have revealed a remarkably different type of hostbacteriophage interaction, pseudolysogeny (Baess, 1971; Ripp \& Miller, 1997). Pseudolysogeny defines a condition in which the starved host cell coexists with its viral genome in an unstable relationship for extended

\footnotetext{
†Present address: Center for Environmental Biotechnology, University of Tennessee, Knoxville, TN 37996, USA

Abbreviations: PBR, phage-to-bacterium ratio; PMM, Pseudomonas Minimal Medium; PMM-C, PMM minus sodium citrate; p.f.u., plaqueforming units.
}

periods. As nutrient supplies are replenished, the viral genome in the pseudolysogenized cell either establishes true lysogeny or becomes activated to produce and release virions. The direct result of pseudolysogenic relationships is the extension of phage genome half-lives in natural, nutrient-limited environments. Ultimately, pseudolysogeny provides a way in which phage can maintain themselves in the large numbers observed in what would appear to be hostile habitats (Bergh et al., 1989; Bratbak \& Heldal, 1993; Hennes \& Suttle, 1995; Paul et al., 1991; Proctor \& Fuhrman, 1990; Walter et al., 1989).

In this study, we have utilized continuous culture methodology to evaluate the pseudolysogenic response in cells growing under increasingly more severe states of starvation. These states were produced by lengthening the hydraulic turnover (generation) times of the chemostat culture or by decreasing carbon availability in the growth medium. In this manner, we assessed pseudolysogenic interactions over a wide range of growth conditions. 


\section{METHODS}

Bacterial strains and bacteriophages. Pseudomonas aeruginosa strains PAO1 (prototrophic) (Miller \& $\mathrm{Ku}, 1978$ ), PAO303 (argB21) (Kokjohn \& Miller, 1988), PAO515 (met9011, amiE200, nalA5) (Rella \& Hass, 1982) and RM132 (an F116 lysogen of PAO303) (Saye et al., 1990) were used in this study. Phage F116 is a temperate, generalized transducing phage (Miller et al., 1974). Phage UT1 was isolated from a natural freshwater lake (Ogunseitan et al., 1990). It exhibits a virulent phenotype under laboratory conditions, but appears pseudolysogenic under natural conditions (Kokjohn et al., 1991). It is also a generalized transducing phage (Ripp et al., 1994).

Media. Luria-Bertani (LB) agar was routinely used as nonselective medium (Miller \& Ku, 1978). Selective media consisted of either LB agar containing nalidixic acid $(500 \mu \mathrm{g}$ $\mathrm{ml}^{-1}$ ) or Pseudomonas Minimal Medium (PMM) containing $0.4 \%$ glucose supplemented with arginine $\left(25 \mu \mathrm{g} \mathrm{ml}^{-1}\right.$ ) (Miller $\& \mathrm{Ku}, 1978)$. Chemostats contained a variation of PMM in which the sodium citrate was omitted (PMM-c) (Replicon et al., 1995). Yeast extract was added at various concentrations, serving as sole source of carbon and nitrogen in continuous culture experiments.

Continuous culture conditions. Four experimental designs were established to assess host-bacteriophage interactions under various levels of host-cell starvation. All experiments utilized a New Brunswick Scientific Bioflo model C30 bench top chemostat (Edison) consisting of a 1 or $1.5 \mathrm{l}$ culture vessel and a 101 medium reservoir containing PMM-c supplemented with yeast extract (Replicon et al., 1995). All incubations were performed at room temperature with aeration at an agitation rate of 200 r.p.m.

The first experimental design evaluated the response of phage F116 to varying nutrient concentrations available to its host cells. Strain RM132 served as the source of phage virions and PAO515 as host. Five separate chemostat runs were performed, each providing a specific level of nutrient in the PMM-c growth medium: $10^{-2}, 10^{-3}, 10^{-4}, 10^{-5}$ and $10^{-6} \%$ yeast extract (final concentration).

The second experimental design exactly repeated the first except that phage UT1 was used instead of F116. Phage UT1 was inoculated directly into the chemostat since it is virulent and no lysogenic strain for it exists. Strain PAO303 served as the source of host cells. Yeast extract concentrations were again maintained at final concentrations of $10^{-2}, 10^{-3}, 10^{-4}$, $10^{-5}$ and $10^{-6} \%$.

The final two experimental designs assessed the response of either F116 or UT1 to changes in host generation times. Chemostat pump speeds were set to produce generation times of either $5,8,10,12$ or $14 \mathrm{~h}$, yielding five treatments for each phage. Host and phage inocula remained the same as for the first two designs, with yeast extract being maintained at a constant $10^{-4} \%$ final concentration throughout each treatment.

Preparation of inocula. Strains inoculated into chemostats were first grown overnight at $37^{\circ} \mathrm{C}$ in $\mathrm{LB}$ broth and then diluted 1:100 in PMM-c supplemented with $0.5 \%$ yeast extract and grown to mid-exponential phase at $37^{\circ} \mathrm{C}$. Cultures were then washed twice in PMM-c (containing no yeast extract) and inoculated into the chemostats. For studies involving phage F116, strains PAO515 and RM132 were inoculated into the culture vessel at approximately $10^{6}$ and
$10^{5}$ c.f.u. $\mathrm{ml}^{-1}$, respectively. Studies involving phage UT1 utilized strain PAO303 inoculated at approximately $10^{6}$ c.f.u. $\mathrm{ml}^{-1}$. After a stabilization period of $4 \mathrm{~d}$, phage UT1, suspended in PMM-c, was added at $10^{5}$ p.f.u. $\mathrm{ml}^{-1}$.

Bacteriophage and infective centre enumeration. Total numbers of bacteriophage were determined through plaque assays (Billing, 1969). Samples were first filtered through $0.45 \mu \mathrm{m}$ syringe filters to remove bacterial cells and then diluted in 100-fold increments in PMM-c. A sample $(0.1 \mathrm{ml})$ of each dilution was combined with $0 \cdot 1 \mathrm{ml}$ of a fresh PAO1 culture in mid-exponential phase to which was added $2.5 \mathrm{ml} \lambda$ top agar (Miller \& Ku, 1978). After gentle vortexing, the mixture was poured onto LB agar plates and incubated at $37^{\circ} \mathrm{C}$. The resulting plaque-forming units (p.f.u.) were counted the next day.

Infective centres refer to bacteria which are in the latent phase of lytic infection (Kokjohn et al., 1991). Quantification of infectious centres was determined in the same manner as bacteriophage counts except that bacterial cells were not filtered out of the samples. As a result, the plaques formed on these plates represented the total numbers of both free phage and infective centres. By subtracting the titre of free phages from this count, the concentration of infective centres could be determined.

Identification of phage-releasing isolates. Potential phagereleasing colonies were isolated from F116-containing chemostats by plating on LB plates containing nalidixic acid $(500 \mu \mathrm{g}$ $\mathrm{ml}^{-1}$ ). For chemostats inoculated with phage UT1, PMM containing $0.4 \%$ glucose supplemented with arginine $(25 \mu \mathrm{g}$ $\mathrm{ml}^{-1}$ ) was used. One hundred colonies per plate were transferred onto a top agar overlay of PAO1 and incubated overnight at $37^{\circ} \mathrm{C}$. A zone of lysis surrounding a colony signified the spontaneous release of virions (Miller $\& \mathrm{Ku}$, 1978).

Identification of pseudolysogenic cells. Colony hybridizations were performed to determine the frequency of cells containing phage DNA. Phage F116 and UT1 genomic DNAs were isolated according to Silhavy et al. (1984) and chemiluminescently labelled with the Genius Non-radioactive Labelling Kit (Boehringer Mannheim). Bacterial colonies isolated from the chemostat culture were transferred onto Magnagraph $0.45 \mu \mathrm{m}$ pore size, $85 \mathrm{~mm}$ diameter nylon membranes (Micron Separations) and hybridized with either the labelled F116 or UT1 probe, according to the Genius system user's guide, version 2.0 (1992). In this manner, the number of cells actually containing a phage genome could be determined and compared to the number of cells actively releasing phage as ascertained by the above agar overlay technique. The difference represents the number of pseudolysogens; those cells containing phage but unable to actively release virions.

\section{RESULTS}

Several studies have assessed host-bacteriophage interactions in chemostat cultures (Chao et al., 1977; Kooi \& Kooijman, 1994; Lenski \& Levin, 1985; Levin et al., 1977). However, none has examined the pseudolysogenic response under continuous culture conditions. The nutrient concentrations and generation : nes established for the numerous chemostat cultures described here were our best approximations of what might occur in a natural freshwater lake (Replicon et al., 1995). However, in a typical environmental situation, param- 

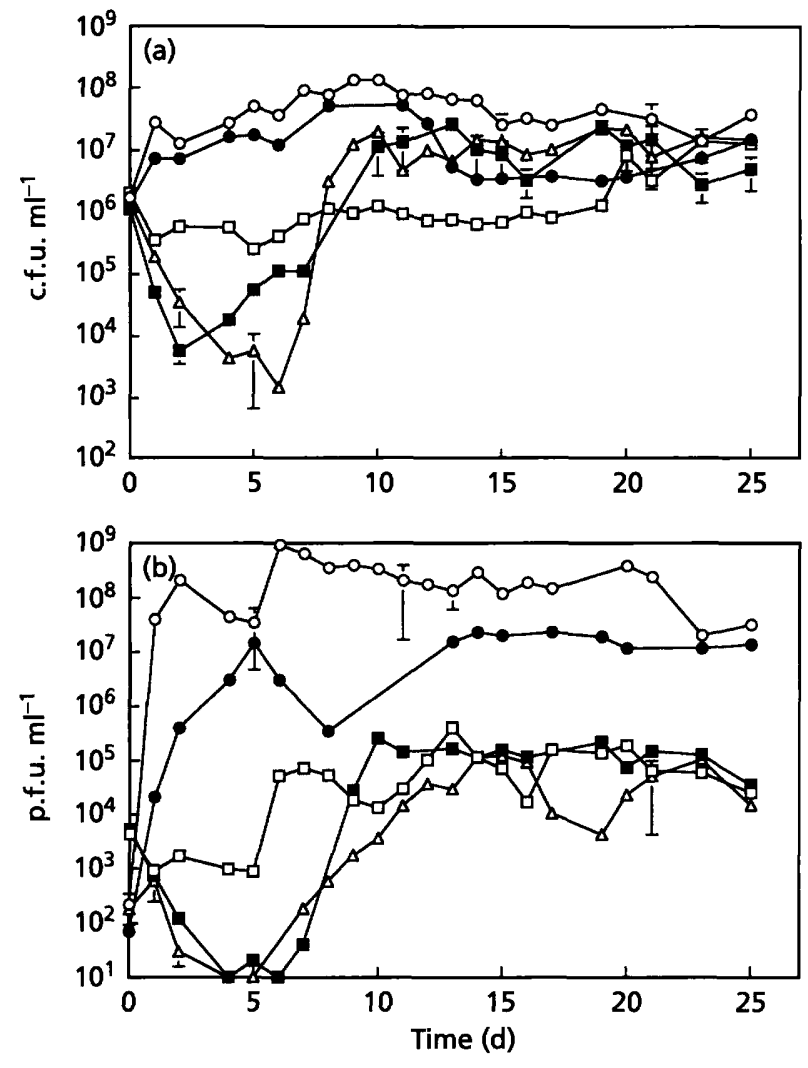

Fig. 1. (a) Colony and (b) phage F116 concentrations in continuous cultures supplemented with yeast extract at $10^{-2}$ $(O), 10^{-3}(O), 10^{-4}(\square), 10^{-5}(\square)$ and $10^{-6} \%(\triangle)$. Error bars represent SEM $(n=3)$.

eters affecting population growth characteristics are essentially too widely varied to undergo precise measurement. Therefore, an extended range of nutrient concentrations and generation times were used in the chemostat simulations to achieve an overall view of host-bacteriophage interactions in the natural environment. Growth rates for each of the strains used in these experiments were established in filter-sterilized lake water (data not shown). Strains typically maintained their populations at levels comparable to those which developed in the chemostats. Exceptions occurred at the extreme low end of the nutrient concentration range. In general, growth in the chemostats was maintained at approximately $10^{5}-10^{8}$ c.f.u. $\mathrm{ml}^{-1}$ and $10^{3}-10^{9}$ p.f.u. $\mathrm{ml}^{-1}$, which closely approximates concentrations found in natural aquatic populations (Bergh et al., 1989; Miller \& Sayler, 1992; Proctor \& Fuhrman, 1990; Suttle, 1994).

\section{Response of phage F116 to variations in nutrient concentrations available to the host bacterium}

Bacterial and phage F116 growth patterns in chemostats supplemented with yeast extract at various concentrations are shown in Fig. 1. As is readily apparent, phage and bacterial populations are maintained at the
Table 1. PBRs in chemostats inoculated with RM132 (the F116 lysogen) and its host PAO515 at varying concentrations of yeast extract

\begin{tabular}{|c|c|c|c|c|c|}
\hline \multirow[t]{2}{*}{ Day } & \multicolumn{5}{|c|}{$\begin{array}{l}10^{-3} \times \text { PBR at final yeast extract concentration } \\
(\%) \text { of: }\end{array}$} \\
\hline & $10^{-2}$ & $10^{-3}$ & $10^{-4}$ & $10^{-5}$ & $10^{-6}$ \\
\hline 0 & $<1$ & $<1$ & 2 & 5 & $<1$ \\
\hline 1 & 1452 & 3 & 3 & 19 & 3 \\
\hline 4 & 1593 & 188 & 3 & $<1$ & 2 \\
\hline 8 & 4667 & 7 & 47 & $<1$ & $<1$ \\
\hline 10 & 2538 & ND & 11 & $<1$ & $<1$ \\
\hline 12 & 2152 & ND & 143 & 179 & 4 \\
\hline 14 & 4667 & 2885 & 180 & 122 & 8 \\
\hline 16 & 5806 & 5758 & 195 & 113 & 11 \\
\hline 19 & ND & 6000 & 108 & 150 & $<1$ \\
\hline 23 & 1462 & 1571 & 18 & 154 & 7 \\
\hline 26 & 857 & 929 & 2 & 156 & 1 \\
\hline
\end{tabular}

ND, Not determined.

highest densities at high yeast extract concentrations and decrease as the concentration of yeast extract decreases. Table 1 lists the ratio of phage particles per bacterium (PBR) (Ogunseitan et al., 1990) that developed over the course of each chemostat run. A rather dramatic difference exists between phage production at high and low nutrient concentrations. However, the exact opposite observation is made when assessing pseudolysogen concentrations (Table 2 ). At $10^{-2} \%$ yeast extract, the frequency of cells that have been pseudolysogenized is minimal but gradually increases until a maximum is attained at $10^{-6} \%$ yeast extract.

This observation is consistent with our hypothesis concerning pseudolysogeny. As cellular starvation levels increase, we would predict that the occurrence of pseudolysogeny would also increase. It is interesting to note that the fraction of cells found to contain the F116 genome (those testing positive in colony hybridizations) increased as nutrient levels decreased. The rate of increase between $10^{-2}$ and $10^{-4} \%$ yeast extract did not, in general, differ. However, there was a substantial difference between these concentrations and the rates observed at $10^{-5}$ and $10^{-6} \%$. These observations correlate well with the larger numbers of pseudolysogens present in the $10^{-5}$ and $10^{-6} \%$ yeast extract experiments.

\section{Response of phage UT1 to variations in nutrient concentrations available to the host bacterium}

When the virulent phage UT1 was grown at various nutrient concentrations, equilibriums were established between phage and host numbers in all cases except at $10^{-6} \%$ yeast extract when phage concentrations began to decline after approximately $28 \mathrm{~d}$ (Fig. 2). However, as phage numbers declined, the number of cells containing phage DNA increased, as can be seen in Table 3 on days 
Table 2. Comparison of the percentage of phage-releasing cells to pseudolysogenic cells in chemostat microcosms inoculated with RM132 and PAO515 at varying concentrations of yeast extract

'Fraction' refers to the number of cells positively identified through colony hybridization to contain phage per total number of cells tested. ' $\%$ act.' refers to the percentage of these cells actively releasing phage. ' $\%$ not act.' refers to the percentage of pseudolysogenic cells. For example, on day 9 at $10^{-2} \%$ yeast extract, 90 colonies out of 300 produced a positive signal when hybridized with labelled F116 DNA. Of these, $86(96 \%)$ actively released phage and $4(4 \%)$ were pseudolysogenic.

\begin{tabular}{|c|c|c|c|c|c|c|c|c|c|c|c|c|c|c|c|}
\hline \multirow[t]{3}{*}{ Day } & \multicolumn{15}{|c|}{ Yeast extract (\%): } \\
\hline & \multicolumn{3}{|c|}{$10^{-2}$} & \multicolumn{3}{|c|}{$10^{-3}$} & \multicolumn{3}{|c|}{$10^{-4}$} & \multicolumn{3}{|c|}{$10^{-5}$} & \multicolumn{3}{|c|}{$10^{-6}$} \\
\hline & Fraction & $\%$ act. & $\%$ not act. & Fraction & $\%$ act. & $\%$ not act. & Fraction & $\%$ act. & $\%$ not act. & Fraction & $\%$ act. & $\%$ not act. & Fraction & $\%$ act. & $\%$ not act. \\
\hline 0 & $1 / 280$ & 100 & $<1$ & $1 / 330$ & 100 & $<1$ & $1 / 220$ & 100 & $<1$ & $1 / 290$ & 100 & 0 & $2 / 140$ & 50 & 50 \\
\hline 9 & $90 / 300$ & 96 & 4 & $2 / 300$ & 100 & $<1$ & $122 / 1140$ & 82 & 18 & $103 / 400$ & 50 & 50 & $60 / 250$ & 57 & 43 \\
\hline 13 & $46 / 340$ & 96 & 4 & $40 / 430$ & 98 & 2 & $62 / 380$ & 89 & 11 & $146 / 580$ & 75 & 25 & $166 / 420$ & 67 & 33 \\
\hline 17 & $52 / 400$ & 90 & 10 & $52 / 620$ & 94 & 6 & $58 / 290$ & 45 & 55 & $186 / 460$ & 63 & 37 & $110 / 260$ & 56 & 44 \\
\hline 25 & $82 / 280$ & 93 & 7 & $38 / 470$ & 95 & 5 & $92 / 360$ & 83 & 17 & $92 / 230$ & 61 & 39 & $127 / 250$ & 59 & 41 \\
\hline
\end{tabular}
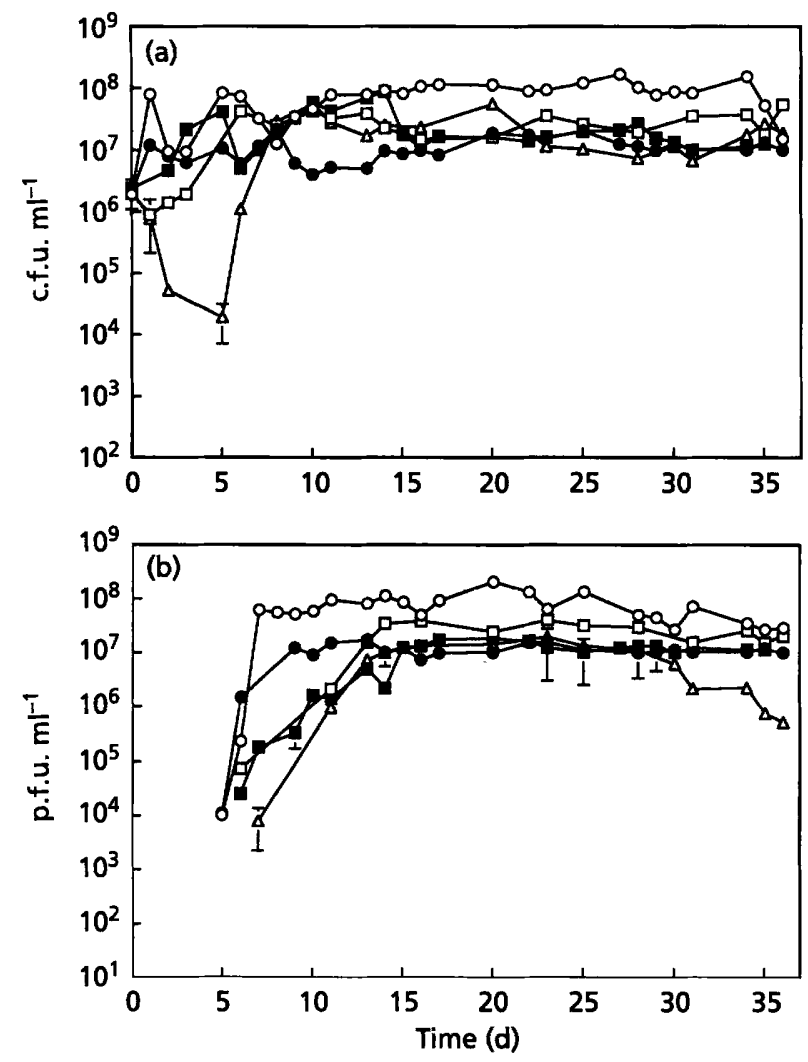

Fig. 2. (a) Colony and (b) phage UT1 concentrations in continuous cultures supplemented with yeast extract at $10^{-2}$ (O), $10^{-3}(O), 10^{-4}(\square), 10^{-5}(\square)$ and $10^{-6} \%(\triangle)$. Error bars represent SEM $(n=3)$.

28 and 35 at $10^{-6} \%$ yeast extract. At these time points, 34 and $46 \%$ of the cells, respectively, were found to exhibit pseudolysogeny. Pseudolysogenic frequencies this large were seen in none of the other microcosms, emphasizing the importance of nutrient limitation to pseudolysogen establishment. In fact, the overall frac- tion of cells exhibiting pseudolysogenic characteristics increased rather dramatically from high to low yeast extract additions (Table 3), just as was seen for phage F116. PBRs generally followed the same pattern as they did for F116 (Table 4). At high nutrient levels, high PBRs were attained almost immediately. As nutrient levels decreased, PBR increases were delayed.

\section{Estimation of phage F116 activities at various host generation times}

The generation time of bacteria growing in a continuous culture is equivalent to the time it takes for the culture vessel to completely replenish itself with medium (Malek \& Fencl, 1966). Mathematically, this is represented as the reciprocal of the dilution rate, $1 / D$, or the ratio of the volume of the culture to the rate at which fresh medium flows into the culture $(V / F)$. Therefore, at short generation times (i.e. $5 \mathrm{~h}$ ), cells are provided with fresh medium at a rapid rate and growth proceeds under conditions of only mild nutrient limitation. As generation times increase, the flow rate of fresh medium decreases such that nutrient addition occurs at a very slow rate. Consequently, the growth environment is severely nutrient-limited and cells exist in a semi-starved state. For the experiments reported here, generation times of $5,8,10,12$ and $14 \mathrm{~h}$ were used at a constant yeast extract concentration of $10^{-4} \%$ (Fig. 3 ).

At generation times of 5 and 8 h, phage F116 concentrations initially increased at a rapid rate, followed by a decline and another increase up to or surpassing hostcell concentrations. Similar results were obtained at 10 , 12 and $14 \mathrm{~h}$ generation times except that phage concentrations initially decreased to well below inoculation levels. This was coincident with an initial drop in cell numbers, as well.

The oscillating phage concentrations seen in all of these cultures is a phenomenon typically associated with predator/prey growth in a closed, regulated system (Gause \& Witt, 1935). Due to this oscillating nature, it 
Table 3. Comparison of the percentage of phage-releasing cells to pseudolysogenic cells in chemostat microcosms inoculated with PAO303 and phage UT1 at varying concentrations of yeast extract

For explanation of terms, see Table 2.

\begin{tabular}{|c|c|c|c|c|c|c|c|c|c|c|c|c|c|c|c|}
\hline \multirow[t]{3}{*}{ Day } & \multicolumn{15}{|c|}{ Yeast extract $(\%)$ : } \\
\hline & \multicolumn{3}{|c|}{$10^{-2}$} & \multicolumn{3}{|c|}{$10^{-3}$} & \multicolumn{3}{|c|}{$10^{-4}$} & \multicolumn{3}{|c|}{$10^{-5}$} & \multicolumn{3}{|c|}{$10^{-6}$} \\
\hline & Fraction & $\%$ act. & $\%$ not act. & Fraction & $\%$ act. & $\%$ not act. & Fraction & $\%$ act. & $\%$ not act. & Fraction & $\%$ act. & $\%$ not act. & Fraction & $\%$ act. & $\%$ not act. \\
\hline 10 & $83 / 400$ & 91 & 9 & $125 / 420$ & 95 & 5 & $54 / 460$ & 90 & 10 & $30 / 280$ & 78 & 22 & $33 / 360$ & 92 & 8 \\
\hline 15 & $92 / 770$ & 92 & 8 & $137 / 880$ & 92 & 8 & $282 / 830$ & 85 & 15 & $75 / 1100$ & 80 & 20 & $412 / 2600$ & 88 & 12 \\
\hline 22 & $20 / 820$ & 100 & $<1$ & $360 / 1800$ & 98 & 2 & $62 / 280$ & 84 & 16 & $78 / 1300$ & 76 & 24 & $342 / 1100$ & 72 & 28 \\
\hline 28 & $60 / 860$ & 100 & $<1$ & $294 / 1200$ & 95 & 5 & $42 / 400$ & 84 & 16 & $45 / 190$ & 80 & 20 & $330 / 660$ & 66 & 34 \\
\hline 35 & $87 / 430$ & 100 & $<1$ & $52 / 120$ & 94 & 6 & $100 / 230$ & 85 & 15 & $82 / 130$ & 75 & 25 & $40 / 100$ & 54 & 46 \\
\hline
\end{tabular}

Table 4. PBRs in chemostats inoculated with PAO303 and phage UT1 at varying concentrations of yeast extract

\begin{tabular}{|rrrrrr|}
\hline Day & \multicolumn{5}{c|}{$\begin{array}{l}10^{-2} \times \text { PBR at final yeast extract } \\
\text { concentration (\%) of: }\end{array}$} \\
\cline { 2 - 6 } & \multicolumn{1}{c}{$\mathbf{1 0}^{-\mathbf{2}}$} & $\mathbf{1 0 ^ { - 3 }}$ & $\mathbf{1 0}^{-4}$ & $\mathbf{1 0}^{-5}$ & $\mathbf{1 0}^{-6}$ \\
\hline 0 & 0 & 0 & 0 & 0 & 0 \\
7 & 194 & $<1$ & ND & $<1$ & ND \\
9 & 150 & 198 & ND & ND & ND \\
10 & 129 & 228 & $<1$ & $<1$ & $<1$ \\
13 & 104 & 347 & 155 & 3 & 41 \\
16 & 47 & 75 & 262 & 7 & 58 \\
17 & 82 & 118 & ND & 4 & 17 \\
20 & 185 & 54 & 155 & 106 & 26 \\
23 & 70 & 100 & 115 & 75 & 173 \\
29 & 59 & 106 & 157 & 124 & 156 \\
30 & 31 & 88 & ND & 113 & ND \\
31 & 87 & 105 & 45 & 92 & 55 \\
34 & 23 & 104 & 71 & ND & 33 \\
35 & 53 & 93 & 88 & ND & 13 \\
\hline
\end{tabular}

ND, Not determined.

is difficult to form a pattern when assessing PBRs. However, in general, phage production decreases as generation times extend (Table 5) and the number of pseudolysogens increases as generation times increase (Table 6). These results are virtually identical to those obtained for phage F116 at differing nutrient concentrations.

\section{Estimation of phage UT1 activities at various host generation times}

These chemostat experiments differed from all others in that phages were consistently maintained at slightly higher levels than were their host cells (Fig. 4). This is analogous to what was seen by Levin et al. (1977) in a similar one resource/one prey/one predator chemostat model using Escherichia coli and phage T2. Why our
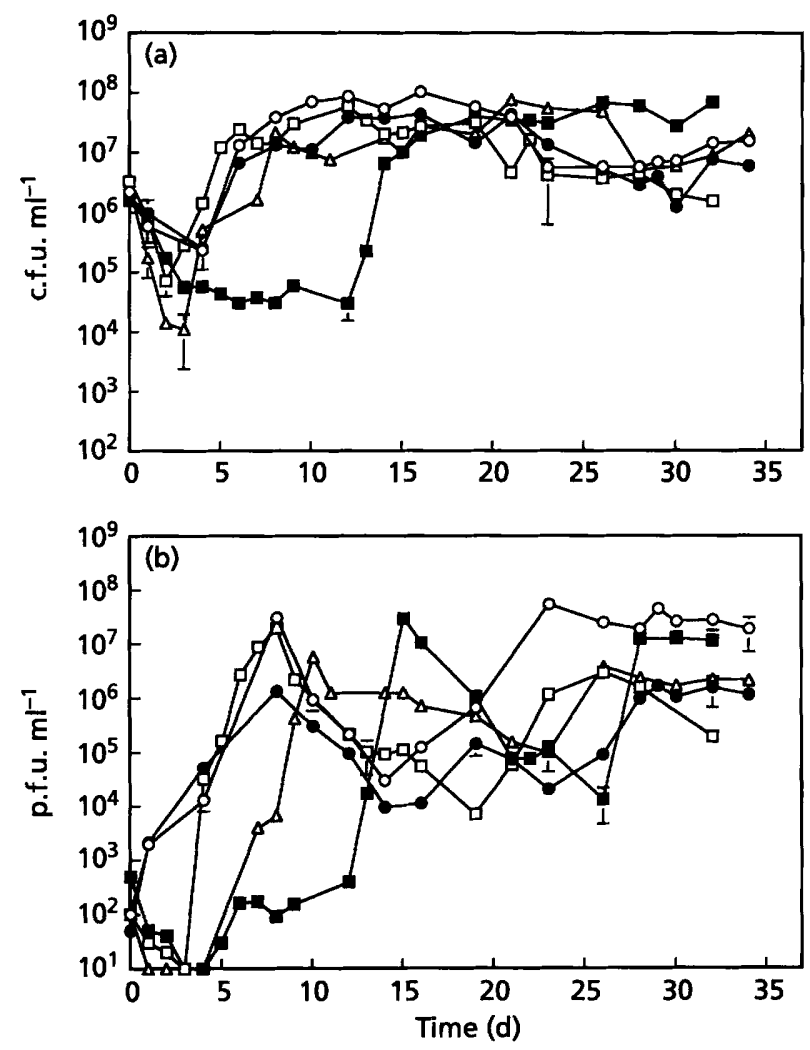

Fig. 3. (a) Colony and (b) phage F116 concentrations in continuous cultures operating at generation times of $5(O), 8$ (O), $10(\square), 12(\square)$ and $14 \mathrm{~h}(\triangle)$. Error bars represent SEM $(n=$ 3).

other chemostat runs did not behave in this manner is unknown. However, other studies have not confirmed Levin's model either (Chao et al., 1977; Lenski \& Levin, 1985), pointing out the fact that our understanding of predator/prey relationships under low nutrient conditions is severely limited.

However, our concerns lie not in explaining these relationships, but with understanding pseudolysogeny. As such, it was again evident that pseudolysogeny occurred much more frequently at longer generation 
Table 5. PBRs in chemostats inoculated with RM132 and PAO515 at varying generation times

\begin{tabular}{|rrrrrr|}
\hline \multirow{2}{*}{ Day } & \multicolumn{5}{c}{$\mathbf{1 0}$-2 $\times$ PBR at generation time (h) of: } \\
\cline { 2 - 6 } & \multicolumn{1}{c}{5} & \multicolumn{1}{c|}{$\mathbf{5}$} & 10 & 12 & 14 \\
\hline 0 & $<1$ & $<1$ & $<1$ & $<1$ & $<1$ \\
1 & 3 & 2 & $<1$ & $<1$ & $<1$ \\
4 & 57 & 204 & 23 & $<1$ & $<1$ \\
8 & 789 & 100 & 1357 & 3 & $<1$ \\
10 & 13 & 27 & 70 & 3 & 567 \\
12 & 3 & 2 & 4 & 13 & 120 \\
14 & $<1$ & $<1$ & 5 & 77 & 23 \\
16 & 1 & $<1$ & 2 & 526 & 2 \\
19 & 12 & 10 & $<1$ & 26 & 23 \\
23 & 9455 & 2 & 268 & 4 & 2 \\
26 & 4286 & 17 & 778 & $<1$ & 77 \\
27 & 3214 & 336 & 349 & 203 & 431 \\
29 & 6324 & 410 & ND & 444 & 276 \\
30 & 3521 & 833 & 127 & 164 & 244 \\
\hline
\end{tabular}

ND, Not determined.

times when cells were more starved (Table 7). PBRs were fairly equal among all generation times (Table 8), but once again, phage concentrations tended to oscillate, making an accurate analysis of the PBR difficult. Also, high PBRs at 12 and $14 \mathrm{~h}$ generation times were caused by a decrease in cell numbers and not an overall increase in phage concentrations.

\section{DISCUSSION}

In our continuous culture studies on pseudolysogeny, the temperate phage F116 behaved much more interestingly than the virulent UT1 phage. Phage F116 tended to follow classical Gause-type oscillations with a coincident reciprocal bacterial oscillation sometimes occurring as well (Gause \& Witt, 1935). This behaviour was explained in detail by Chao et al. (1977). When the phage and bacterial populations are low, bacterial numbers tend to increase since cell division occurs more
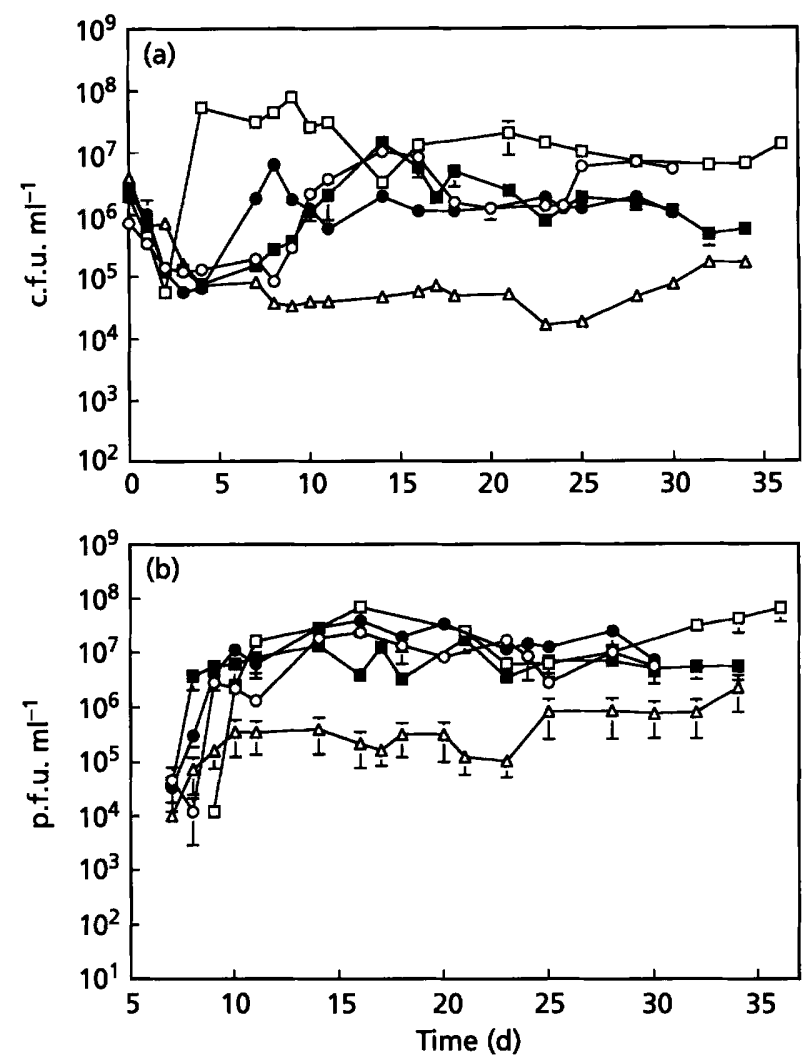

Fig. 4. (a) Colony and (b) phage UT1 concentrations in continuous cultures operating at generation times of $5(O)$, $8(0), 10(\square), 12(\square)$ and $14 \mathrm{~h}(\triangle)$. Error bars represent SEM $(n=3)$.

quickly than phage infection events. However, when bacterial concentrations are high, phage infection rates dramatically increase and the phage population rises while bacterial numbers fall. The continuous flow of nutrients into the chemostat provides the few remaining cells with sufficient energy to maintain high growth rates while the continuous removal of wastes decreases the phage population. Bacterial concentrations now increase as phage numbers fall and the cycle repeats. In these studies, although oscillations occurred, bacterio-

Table 6. Comparison of the percentage of phage-releasing cells to pseudolysogenic cells in chemostat microcosms inoculated with RM132 and PAO515 at varying generation times

For explanation of terms, see Table 2.

\begin{tabular}{|c|c|c|c|c|c|c|c|c|c|c|c|c|c|c|c|}
\hline \multirow[t]{3}{*}{ Day } & \multicolumn{15}{|c|}{ Generation time (h): } \\
\hline & \multicolumn{3}{|c|}{5} & \multicolumn{3}{|c|}{8} & \multicolumn{3}{|c|}{10} & \multicolumn{3}{|c|}{12} & \multicolumn{3}{|c|}{14} \\
\hline & Fraction & $\%$ act. & $\%$ not act. & Fraction & $\%$ act. & $\%$ not act. & Fraction & $\%$ act. & $\%$ not act. & Fraction & $\%$ act. & $\%$ not act. & Fraction & $\%$ act. & $\%$ not act. \\
\hline 0 & $1 / 220$ & 100 & 0 & $2 / 210$ & 100 & 0 & $1 / 280$ & 100 & 0 & $1 / 320$ & 100 & 0 & $1 / 150$ & 100 & 0 \\
\hline 9 & $48 / 300$ & 96 & 4 & $41 / 290$ & 100 & 0 & $148 / 250$ & 93 & 7 & $2 / 140$ & 50 & 50 & $6 / 170$ & 17 & 83 \\
\hline 19 & $60 / 350$ & 98 & 2 & $46 / 380$ & 98 & 2 & $245 / 390$ & 92 & 8 & $210 / 490$ & 80 & 20 & $403 / 1185$ & 79 & 21 \\
\hline 23 & $55 / 390$ & 96 & 4 & $51 / 320$ & 96 & 4 & $224 / 350$ & 89 & 11 & $189 / 360$ & 77 & 23 & $189 / 450$ & 81 & 19 \\
\hline 28 & $68 / 350$ & 96 & 4 & $51 / 300$ & 94 & 6 & $153 / 330$ & 87 & 13 & $245 / 590$ & 76 & 24 & $88 / 129$ & 82 & 18 \\
\hline
\end{tabular}


Table 7. Comparison of the percentage of phage-releasing cells to pseudolysogenic cells in chemostat microcosms inoculated with PAO303 and phage UT1 at varying generation times

For explanation of terms, see Table 2.

\begin{tabular}{|c|c|c|c|c|c|c|c|c|c|c|c|c|c|c|c|}
\hline \multirow[t]{3}{*}{ Day } & \multicolumn{15}{|c|}{ Generation time $(\mathrm{h})$ : } \\
\hline & \multicolumn{3}{|c|}{5} & \multicolumn{3}{|c|}{8} & \multicolumn{3}{|c|}{10} & \multicolumn{3}{|c|}{12} & \multicolumn{3}{|c|}{14} \\
\hline & Fraction & $\%$ act. & $\%$ not act. & Fraction & $\%$ act. & $\%$ not act. & Fraction & $\%$ act. & $\%$ not act. & Fraction & $\%$ act. & $\%$ not act. & Fraction & $\%$ act. & $\%$ not act. \\
\hline 9 & $482 / 2800$ & 89 & 11 & $32 / 160$ & 80 & 20 & $0 / 330$ & 0 & 0 & $9 / 150$ & 57 & 43 & $2 / 120$ & 50 & 50 \\
\hline 16 & $270 / 1100$ & 84 & 16 & $307 / 1200$ & 76 & 24 & $162 / 330$ & 70 & 30 & $29 / 130$ & 53 & 47 & $110 / 300$ & 62 & 38 \\
\hline 24 & $30 / 140$ & 70 & 30 & $247 / 1200$ & 62 & 38 & $216 / 1500$ & 79 & 21 & $64 / 620$ & 90 & 10 & $143 / 1800$ & 78 & 22 \\
\hline 30 & $22 / 490$ & 80 & 20 & $86 / 1101$ & 89 & 11 & $67 / 580$ & 83 & 17 & $24 / 110$ & 36 & 64 & $209 / 760$ & 43 & 57 \\
\hline
\end{tabular}

Table 8. PBRs in chemostats inoculated with PAO303 and phage UT1 at varying generation times

\begin{tabular}{|rrrrrr|}
\hline \multirow{2}{*}{ Day } & \multicolumn{5}{c}{$10^{-2} \times$ PBR at generation time (h) of: } \\
\cline { 2 - 6 } & \multicolumn{1}{c}{5} & $\mathbf{8}$ & $\mathbf{1 0}$ & 12 & \multicolumn{1}{c|}{$\mathbf{1 4}$} \\
\hline & & & & & \\
0 & 0 & 0 & 0 & 0 & 0 \\
7 & 25 & 2 & ND & 28 & 91 \\
8 & 14 & 5 & ND & 1396 & 438 \\
9 & 982 & 230 & ND & 1528 & 1061 \\
10 & 107 & 917 & $<1$ & 571 & 883 \\
13 & 178 & 1052 & 875 & 96 & 457 \\
16 & 288 & 1474 & 544 & 70 & 294 \\
17 & 897 & 3602 & ND & 667 & 453 \\
20 & 696 & 2727 & 123 & 756 & 240 \\
23 & 1280 & 611 & 44 & 450 & 625 \\
29 & 145 & 1333 & 144 & 447 & 1824 \\
30 & 105 & 660 & ND & 457 & 1028 \\
31 & ND & ND & 513 & 1169 & 503 \\
34 & ND & ND & 661 & 964 & 1375 \\
\hline
\end{tabular}

ND, Not determined.

phages tended to sustain their concentrations close in number to host populations, except under very low nutrient conditions when phages maintained themselves at one- to twofold lower levels. This resulted in low PBRs. However, PBRs in general agreed with the PBRs generated in in situ incubated lake water microcosms containing phage F116 (Kokjohn et al., 1991; Saye et al., 1990), assuring us that our data from chemostat experiments did mimic in situ data.

The virulent phage, UT1, consistently maintained its population density in equilibrium with or above that of its host except at a yeast extract concentration of $10^{-6} \%$ when phage populations began to decline after $30 \mathrm{~d}$ incubation (Fig. 4). PBRs remained more or less consistent between all experiments, except for transient epidemics where large phage increases were seen due to temporary decreases in host-cell populations. Ogunseitan et al. (1990), using phage UT1, found PBRs to range from $<1$ to approximately 2700 in in situ experiments, which closely agrees with the PBRs generated here.

Assessment of pseudolysogen activity, as measured by the number of cells containing a phage genome but not actively releasing phage, was found to be highly dependent on nutrient concentration. As cells became more starved, concentrations of pseudolysogens tended to increase. The effect of varying the concentration of yeast extract 100 -fold was more dramatic than varying generation times. Significant differences [KolmogrovSmirnov test, $P=0.05$ (Siegel, 1956; Systat, 1992)] were found between each group $\left(10^{-2}, 10^{-3}, 10^{-4}, 10^{-5}\right.$ and $10^{-6} \%$ yeast extract) in both the F116 and UT1 phage experiments. Alteration of generation times between 5 and $8 \mathrm{~h}$ produced no significant differences for either F116 or UT1. Nor were differences found for UT1 between 5 and 10, 8 and 10, and 12 and $14 \mathrm{~h}$ generation times. All other comparisons of generation times were statistically significant.

Replicon et al. (1995), using continuous culture chemostats, have developed a model identifying factors that influence transduction frequency under conditions reminiscent of those encountered by microbial organisms in natural ecosystems. Transduction is a concern because of the potential for horizontal gene transmission from an introduced genetically engineered micro-organism (GEM) to members of the indigenous population. They concluded that transduction can stabilize a phenotype in a genetically heterogeneous microbial population even if that phenotype occurs with a selective disadvantage. The rate of transduction was found to correlate directly with the PBR. Our results further enhance this model by additionally showing that PBRs correlate with nutrient concentration and generation time. Therefore, as cells begin to enter a period of starvation and slow growth, PBRs will decrease as will transduction rates. However, due to the presence of pseudolysogenic cells, any influx of nutrient will dramatically elevate PBRs, thus increasing transduction rates as well. These effects are important when considering the application of GEMs to environmental systems. Stabilization of the phenotype will result in an increased fitness of the released organism which will raise both its survivability and the probability of transferring its genetic material to the indigenous 
microbiota. These consequences must be taken into account in determining the risk associated with the application of GEMs in an environmental setting.

\section{ACKNOWLEDGEMENTS}

This study was supported by a cooperative agreement from the US EPA Environmental Research Laboratory, Gulf Breeze, FL, USA, no. CR820060.

\section{REFERENCES}

Baess, I. (1971). Report on a pseudolysogenic mycobacterium and a review of the literature concerning pseudolysogeny. Acta Pathol Microbiol Scand 79, 428-434.

Bergh, O., Borsheim, K. Y., Bratbak, G. \& Heldal, M. (1989). High abundance of viruses found in aquatic environments. Nature 340 , $467-468$.

Billing, E. (1969). Isolation, growth and preservation of bacteriophages. In Methods in Microbiology, pp. 315-329. Edited by J. R. Norris \& D. W. Ribbons. New York: Academic Press.

Bratbak, G. \& Heldal, M. (1993). Total count of viruses in aquatic environments. In Handbook of Methods in Aquatic Microbial Ecology, pp. 135-138. Edited by P. Kemp, B. F. Sherr, E. B. Sherr \& J. J. Cole. Boca Raton, FL: Lewis Publishers.

Chao, L., Levin, B. R. \& Stewart, F. M. (1977). A complex community in a simple habitat: an experimental study with bacteria and phage. Ecology 58, 369-378.

Gause, G. F. \& Witt, A. A. (1935). Behavior of mixed populations and the problems of natural selection. Am Nat 69, 596-609.

Hennes, K. P. \& Suttle, C. A. (1995). Direct counts of viruses in natural waters and laboratory cultures by epifluorescence microscopy. Limnol Oceanogr 40, 1050-1055.

Kokjohn, T. A. \& Miller, R. V. (1988). Characterization of the Pseudomonas aeruginosa recA gene: the $\mathrm{Les}^{-}$phenotype. $J$ Bacteriol 170, 578-581.

Kokjohn, T. A., Sayler, G. S. \& Miller, R. V. (1991). Attachment and replication of Pseudomonas aeruginosa bacteriophages under conditions simulating aquatic environments. J Gen Microbiol $137,661-666$.

Kooi, B. W. \& Kooijman, S. A. L. M. (1994). Existence and stability of microbial prey - predator systems. J Theor Biol 170, 75-85.

Lenski, R. E. \& Levin, B. R. (1985). Constraints on the coevolution of bacteria and virulent phage: a model, some experiments and predictions for natural communities. Am Nat 125, 585-602.

Levin, B. R., Stewart, F. M. \& Chao, L. (1977). Resource-limited growth, competition and predation: a model and experimental studies with bacteria and bacteriophage. Am Nat 111, 3-24.

Malek, I. \& Fencl, Z. (1966). Theoretical and Methodological Basis of Continuous Culture of Microorganisms. New York: Academic Press.
Miller, R. V. \& Ku, C. M. C. (1978). Characterization of Pseudomonas aeruginosa mutants deficient in the establishment of lysogeny. J Bacteriol 134, 875-883.

Miller, R. V. \& Sayler, G. S. (1992). Bacteriophage-host interactions in aquatic systems. In Genetic Interactions Among Microorganisms in the Natural Environment, pp. 176-193. Edited by E. M. Wellington \& J. D. van Elsas. Oxford: Pergamon Press.

Miller, R. V., Pemberton, J. M. \& Richards, K. E. (1974). F116, D3 and G101: temperate bacteriophages of Pseudomonas aeruginosa. Virology 59, 566-569.

Ogunseitan, O. A., Sayler, G. S. \& Miller, R. V. (1990). Dynamic interactions of Pseudomonas aeruginosa and bacteriophages in lakewater. Microb Ecol 19, 171-185.

Paul, J. H., Jiang, S. C. \& Rose, J. B. (1991). Concentration of viruses and dissolved DNA from aquatic environments by vortex flow filtration. Appl Environ Microbiol 57, 2197-2204.

Proctor, L. M. \& Fuhrman, J. A. (1990). Viral mortality of marine bacteria and cyanobacteria. Nature 343, 60-62.

Rella, M. \& Hass, D. (1982). Resistance of Pseudomonas aeruginosa PAO to nalidixic acid and low levels of $\beta$-lactam antibiotics: mapping of chromosomal genes. Antimicrob Agents Chemother 22, 242-249.

Replicon, J., Frankfater, A. \& Miller, R. V. (1995). A continuous culture model to examine factors that affect transduction among Pseudomonas aeruginosa strains in freshwater environments. Appl Environ Microbiol 61, 3359-3366.

Ripp, S. \& Miller, R. V. (1997). The role of pseudolysogeny in bacteriophage-host interactions in a natural freshwater environment. Microbiology 143, 2065-2070.

Ripp, S., Ogunseitan, O. A. \& Miller, R. V. (1994). Transduction of a freshwater microbial community by a new Pseudomonas aeruginosa generalized transducing phage, UT1. Mol Ecol 3, 121-126.

Saye, D. J., Ogunseitan, O. A., Sayler, G. S. \& Miller, R. V. (1990). Transduction of linked chromosomal genes between Pseudomonas aeruginosa during incubation in situ in a freshwater habitat. Appl Environ Microbiol 56, 140-145.

Siegel, S. (1956). Nonparametric Statistics. New York : McGrawHill.

Silhavy, T. J., Berman, M. L. \& Enquist, L. W. (1984). Experiments with Gene Fusions. Cold Spring Harbor, NY: Cold Spring Harbor Laboratory.

Suttle, C. A. (1994). The significance of viruses to mortality in aquatic microbial communities. Microb Ecol 28, 237-243.

Systat (1992). Statistics, Version 5.2. Evanston, IL: Systat.

Walter, R., Macht, W., Durkop, J., Hecht, R., Hornig, U. \& Schulze, P. (1989). Virus levels in river waters. Water Res 23, 133-138.

Received 21 January 1998; revised 24 March 1998; accepted 14 April 1998. 